\title{
Impact of pulmonary hypertension on transplant outcomes in pediatric cardiomyopathy patients
}

Buddhe S, Du W, L'Ecuyer T. Impact of pulmonary hypertension on transplant outcomes in pediatric cardiomyopathy patients.

Abstract: Controversy exists over whether PHTN in heart transplant candidates increases post-transplant mortality. We performed analysis of data reported to UNOS for children who underwent primary heart transplantation for cardiomyopathy from January 1994 to June 2010. Patients were divided into two groups depending on their pre-transplant TPG: no-PHTN (TPG $\leq 12 \mathrm{mmHg}$ ) and PHTN (TPG $>12 \mathrm{~mm} \mathrm{Hg}$ ). A total of 6139 children underwent transplantation of whom 2456 $(40 \%)$ were for cardiomyopathies; $1322(54 \%)$ of these had catheterization data available. The PHTN group (mean TPG $19.5 \pm 8.6$ ) had 312 patients and no-PHTN (TPG $6.7 \pm 4.0$ ) had 1010. Mortality at one month $(4.5 \%$ vs. $2.3 \%)$ and three months $(6.1 \%$ vs. $3.1 \%)$ posttransplant was significantly higher in the PHTN than the no-PHTN group with an odds ratio of $2(\mathrm{p}<0.05)$. There was no significant effect of PHTN on early mortality in children $<1 \mathrm{yr}$ age. There was no significant improvement in early survival for transplants performed after compared to before 2003 in patients with PHTN despite availability of pulmonary dilators. Pre-transplant PHTN increases early post-transplant mortality in pediatric cardiomyopathy patients above one yr of age. There has been no significant improvement in the outcome of this group over the last seven yr.

\section{Sujatha Buddhe, Wei Du and Thomas L'Ecuyer}

Section of Pediatric Cardiology, Carmen and Ann Adams Department of Pediatrics, The Children's Hospital of Michigan, Wayne State University School of Medicine, Detroit, MI, USA

Key words: pulmonary hypertension - heart transplantation - cardiomyopathy - pediatrics outcomes

Sujatha Buddhe, MD, Section of Pediatric Cardiology, Carmen and Ann Adams Department of Pediatrics, The Children's Hospital of Michigan, Wayne State University School of Medicine, 3901 Beaubien Blvd, Detroit, MI 48201, USA

Tel.: 3137455481

Fax: 3139930894

E-mail: drbuddhe@gmail.com

Accepted for publication 2 February 2012
PHTN has historically been shown to be a significant risk factor for morbidity and mortality in patients awaiting heart transplantation. In this setting, acute donor right heart failure may develop requiring inotropic support, ECMO, prolonged ventilation, and this may even cause mortality. Elevation of both trans-pulmonary pressure gradient and PVR has been identified as risk factors for early morbidity and mortality after heart transplantation (1-3). Even modest

\footnotetext{
Abbreviations: CMP, cardiomyopathy; DCM, dilated cardiomyopathy; DRWR, donor-to-recipient weight ratio; ECMO, extracorporeal membrane oxygenation; HCM, hypertrophic cardiomyopathy; PGE1, prostaglandin E1; PHTN, pulmonary hypertension; PVR, pulmonary vascular resistance; RCM, restrictive cardiomyopathy; TPG, transpulmonary gradient; UNOS, United Network for Organ Sharing.
}

degrees of PHTN can complicate post-transplant management (4) and severe PHTN is thus considered a contraindication to heart transplantation.

Recent studies have suggested that PHTN may not continue to be a significant risk factor (5) for transplant outcome, reflecting availability of new agents useful in management. These studies have been limited by small patient numbers (6), and data are scarce in children (7).

Most studies describing effects of PHTN on transplant outcomes have combined multiple diagnoses (8). In this study, we sought to evaluate pediatric heart transplant outcomes of patients with cardiomyopathies alone. We have restricted focus to patients with cardiomyopathies as in this disease PHTN is thought to be secondary to elevated left ventricular end-diastolic pressure, so it is expected to be reversible 
with placement of a normal heart. Our aim is to compare the post heart transplant mortality and morbidity of children with cardiomyopathies and PHTN to children with normal pulmonary pressures, examining effects of patient age and era.

\section{Methodology}

We performed a retrospective analysis of all data reported to the UNOS database for pediatric patients (ages from 0 to $18 \mathrm{yr}$ ) who underwent primary heart transplantation from January 1994 to June 2010 for a diagnosis of cardiomyopathy. Children with congenital heart disease requiring heart transplant were excluded because they can have PHTN from multiple mechanisms. Catheterization data were not available on all patients in the database, so we included only patients with pre-transplant pulmonary pressure data available. We used the TPG as a measure of PHTN rather than PVR as PVR is cardiac output dependant and these patients generally have low cardiac output, making small variations in cardiac output have a large impact on calculated PVR. TPG was calculated by the difference between the mean pulmonary artery pressure and mean pulmonary capillary wedge pressure.

Patients with cardiomyopathy were divided into two groups based on their pre-transplant TPG: no-PHTN (TPG $\leq 12 \mathrm{mmHg}$ ) and PHTN (TPG $>12 \mathrm{mmHg}$ ). Demographic data gathered included gender, race, and age at transplantation. Clinical characteristics gathered included medical urgency status at transplantation, transplant wait time, need for ventilation, inotropic support, ECMO, need for pre-transplant dialysis, rate of infections requiring antibiotics, and DRWR. Demographic and clinical characteristics were compared between groups. Measures of early post-transplant morbidity were gathered including length of hospital stay after transplantation, need for post-transplant dialysis, rate of posttransplant infection, and incidence of acute rejection. Mortality was compared between groups at one month, three months, one yr, and for the entire post-transplant period separately.

Statistical analysis was performed using SAS version 9.2 (Cary, NC, USA). Demographics pre- and post-transplant characteristics were compared between groups using Fishers exact and chi-square tests. T-test and Mann-Whitney $U$-test were used to compare continuous variables such as age, transplant wait time, ischemic time and length of hospital stay between patient subgroups. Mean and standard deviation were calculated for all continuous variables. Actuarial survival curves were derived using KaplanMeier's product-limit method, and log-rank tests were performed to compare survival between patient subgroups univariately. Cox proportional hazard regression was used to correlate patients' pre-transplant characteristics with duration of survival.

As the UNOS Standard Analysis and Research files provide de-identified data, consent exemption status was granted by the Wayne State University Institutional Review Board.

\section{Results}

A total of 6139 children underwent heart transplantation from January 1994 to June 2010, of which $2456(40 \%)$ had a listing diagnosis of cardiomyopathy. One thousand three hundred and twenty-two (54\%) of cardiomyopathy patients had catheterization data available and thus qualified for the study. Among them, only 52 $(3.9 \%)$ were lost to follow-up. Cardiomyopathy patients without catheterization data available had a significantly lower overall mortality than those with catheterization data $(22 \%$ vs. $27 \%$; $\mathrm{p}<0.01)$. On a covariate adjusted basis, the mortality between catheter and non-catheter patients was not significantly different.

The study group comprised 312 patients in the PHTN group and 1010 in the no-PHTN group. Patient demographics are presented in Table 1. Age, gender, and racial distribution did not differ between groups.

Clinical characteristics are shown in Table 2. Transplant wait time was significantly longer in the PHTN group $(\mathrm{p}=0.01)$. Indicators of pretransplant severity such as medical urgency status need for mechanical ventilation, inotropic support, ECMO support, dialysis, and infections requiring antibiotic use were not different between

Table 1. Demographics

\begin{tabular}{|c|c|c|c|}
\hline & $\begin{array}{l}\text { PHTN group } \\
(\mathrm{N}=312)\end{array}$ & $\begin{array}{l}\text { No-PHTN group } \\
(\mathrm{N}=1010)\end{array}$ & $\mathrm{p}$-Value \\
\hline Age, mean \pm s.d. & $9.3 \pm 6.0$ & $9.6 \pm 6.3$ & 0.3 \\
\hline$<1$ yr (N = 130), n (\%) & $26(8)$ & $104(10)$ & \\
\hline $1-10$ yr (N = 502), n (\%) & $128(41)$ & $374(37)$ & \\
\hline$>10$ yr $(\mathrm{N}=690), \mathrm{n}(\%)$ & $158(51)$ & $532(53)$ & \\
\hline \multicolumn{4}{|l|}{ Gender, n (\%) } \\
\hline Male & $176(56)$ & $535(53)$ & 0.3 \\
\hline Female & $136(44)$ & $475(47)$ & \\
\hline \multicolumn{4}{|l|}{ Race, n (\%) } \\
\hline Caucasian & $153(49)$ & $545(54)$ & 0.2 \\
\hline African American & $81(26)$ & $270(27)$ & \\
\hline Hispanic & $48(15)$ & $121(12)$ & \\
\hline Other & $30(10)$ & $74(7)$ & \\
\hline
\end{tabular}


Table 2. Clinical characteristics

\begin{tabular}{|c|c|c|c|}
\hline & $\begin{array}{l}\text { PHTN group } \\
(\mathrm{N}=312)\end{array}$ & $\begin{array}{l}\text { No-PHTN group } \\
(\mathrm{N}=1010)\end{array}$ & p-Value \\
\hline \multicolumn{4}{|l|}{ Urgency status, n (\%) } \\
\hline $1 \mathrm{~A}$ & $143(46)$ & $541(54)$ & \multirow[t]{4}{*}{0.09} \\
\hline $1 \mathrm{~B}$ & $40(13)$ & $103(10)$ & \\
\hline 2 & $59(19)$ & $179(18)$ & \\
\hline Other & $70(22)$ & $187(18)$ & \\
\hline $\mathrm{TPG}$, mean \pm s.d. & $19.5 \pm 8.6$ & $6.7 \pm 4.0$ & $<0.01$ \\
\hline \multicolumn{4}{|l|}{ Diagnosis, n (\%) } \\
\hline Dilated CMP & $238(76)$ & $873(86)$ & \multirow[t]{3}{*}{$<0.01$} \\
\hline Restrictive CMP & 58 (19) & $93(9)$ & \\
\hline Hypertrophic CMP & $16(5)$ & $44(4)$ & \\
\hline $\begin{array}{l}\text { Use of inotropes/vasodilators, } \\
\mathrm{n}(\%)\end{array}$ & $117(37.5)$ & $325(32)$ & 0.08 \\
\hline $\begin{array}{l}\text { Transplant wait time (days), } \\
\text { mean } \pm \text { s.d. }\end{array}$ & $112 \pm 14$ & $86 \pm 5$ & 0.01 \\
\hline Inotropic support Y, n (\%) & $179(57)$ & 547 (54) & 0.3 \\
\hline Ventilation support $Y, n(\%)$ & $42(13)$ & $113(11)$ & 0.3 \\
\hline ECMO support $Y, n(\%)$ & $14(4)$ & $24(2)$ & 0.07 \\
\hline \multicolumn{4}{|l|}{ DRWR, n (\%) } \\
\hline Low $(<0.8)$ & $29(9)$ & $79(8)$ & \multirow[t]{3}{*}{0.4} \\
\hline Ideal $(0.8-2.0)$ & $254(83)$ & $860(85)$ & \\
\hline Oversized $(>2.0)$ & $25(8)$ & $66(7)$ & \\
\hline Dialysis support Y, n (\%) & $5(2)$ & $21(2)$ & 0.8 \\
\hline IV antibiotic support $\mathrm{Y}, \mathrm{n}(\%)$ & $54(17)$ & $145(14)$ & 0.4 \\
\hline Ischemic time (h), mean \pm s.d. & $3.2 \pm 1.3$ & $3.1 \pm 1.0$ & 0.4 \\
\hline Ischemic time $>4$ h Y, $\mathrm{n}(\%)$ & $55(18)$ & $182(18)$ & 1.0 \\
\hline
\end{tabular}

Table 3. Post-transplant morbidity

\begin{tabular}{|c|c|c|c|}
\hline & $\begin{array}{l}\text { PHTN } \\
\text { group } \\
(\mathrm{N}=312)\end{array}$ & $\begin{array}{l}\text { No-PHTN } \\
\text { group } \\
(\mathrm{N}=1010)\end{array}$ & p-Value \\
\hline Cardiac re-operation Y, n (\%) & $17(5)$ & $47(5)$ & 0.5 \\
\hline Dialysis support $Y, n(\%)$ & $10(3)$ & $29(3)$ & 0.7 \\
\hline $\begin{array}{l}\text { Acute rejection before } \\
\text { discharge } Y, n(\%)\end{array}$ & $16(5)$ & $69(7)$ & 0.8 \\
\hline Rejection within 1 yr Y, n (\%) & 81 (26) & $253(25)$ & 0.1 \\
\hline Drug treated infection $\mathrm{Y}, \mathrm{n}(\%)$ & $49(16)$ & $133(13)$ & 0.3 \\
\hline Hospital stay (days), mean \pm s.d. & $20.5 \pm 1.7$ & $19.6 \pm 0.9$ & 0.6 \\
\hline
\end{tabular}

groups. A similar percentage of patients were on inotropes/vasodilators at the time of obtaining hemodynamics in both groups. The DRWR distribution, ischemic time, and number of patients receiving hearts with $\geq 4 \mathrm{~h}$ ischemic time were not significantly different between groups.

Post-transplant morbidity was compared between the groups as shown in Table 3. Duration of hospital stay prior to discharge, need for reoperation, post-transplant dialysis, and incidence of post-transplant infections were similar between groups. The number of acute rejection episodes before discharge and within one yr posttransplant was not significantly different between groups.

Post-transplant mortality is compared between groups in Table 4. In the entire group, mortality
Table 4. Post-transplant mortality

\begin{tabular}{|c|c|c|c|}
\hline & $\begin{array}{l}\text { PHTN } \\
\text { group } \\
(\mathrm{N}=312)\end{array}$ & $\begin{array}{l}\text { No-PHTN } \\
\text { group } \\
(\mathrm{N}=1010)\end{array}$ & $\mathrm{p}$-Value \\
\hline \multicolumn{4}{|c|}{ 1-month mortality, n (\%) } \\
\hline Infant & $0 / 26(0)$ & 6/104 (6) & 0.6 \\
\hline Children & 14/286 (5) & $17 / 906(2)$ & $<0.01$ \\
\hline All & $14(4.5)$ & $23(2.3)$ & 0.04 \\
\hline All pre-2003 & $9 / 179(5)$ & $19 / 499(4)$ & 0.5 \\
\hline All post-2003 & 5/133 (4) & $4 / 511$ (1) & 0.02 \\
\hline \multicolumn{4}{|c|}{ 3-month mortality, n (\%) } \\
\hline Infant & $1(4)$ & $6(6)$ & 1.0 \\
\hline Children & $18(6)$ & $25(3)$ & 0.01 \\
\hline All & $19(6)$ & $31(3)$ & 0.03 \\
\hline All pre-2003 & $13(7)$ & $25(5)$ & 0.2 \\
\hline All post-2003 & $6(5)$ & $6(1)$ & 0.02 \\
\hline \multicolumn{4}{|c|}{ 1-yr mortality, n (\%) } \\
\hline Infant & $4(15)$ & $8(8)$ & 0.2 \\
\hline Children & $29(10)$ & $63(7)$ & 0.09 \\
\hline All & $33(11)$ & $71(7)$ & 0.05 \\
\hline All pre-2003 & $20(11)$ & $50(10)$ & 0.6 \\
\hline All post-2003 & $13(10)$ & $21(4)$ & 0.01 \\
\hline \multicolumn{4}{|c|}{ Overall mortality, n (\%) } \\
\hline Infant & $5(19)$ & $22(21)$ & 1.0 \\
\hline Children & $92(32)$ & $241(27)$ & 0.07 \\
\hline All & $97(31)$ & $263(26)$ & 0.08 \\
\hline All pre-2003 & $72(40)$ & $199(40)$ & 1.0 \\
\hline All post-2003 & $25(19)$ & $64(12.5)$ & 0.06 \\
\hline
\end{tabular}

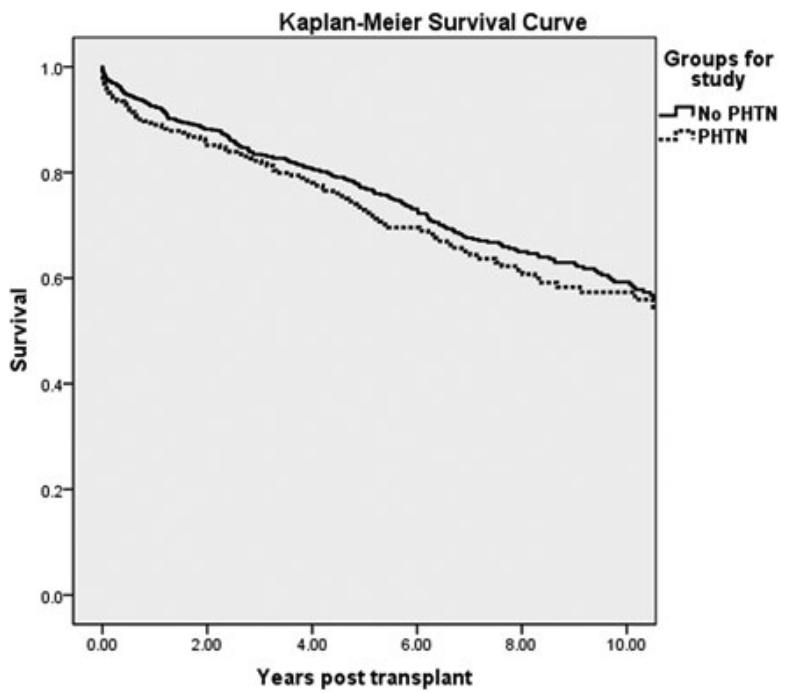

Fig. 1. Kaplan-Meier survival curve. Odds ratio for mortality at one month: 2.0. Odds ratio for mortality at three months: 2.0. Odds ratio for mortality at one yr: 1.6.

at one month $(4.5 \%$ vs. $2.3 \%)$ and three months $(6.1 \%$ vs. $3.1 \%)$ post-transplant was significantly higher in the PHTN than the no-PHTN group. The odds ratio at one and three months for mortality with PHTN is 2.0 and at one yr it is 1.6 $(\mathrm{p}<0.05)$. One $\mathrm{yr}$ and overall mortality was higher in the PHTN group but overall mortality 
did not reach statistical significance (Fig. 1). The hazard ratio for overall mortality for the PHTN group on multivariate analysis was not significant at $0.97(\mathrm{p}=0.97)$. When used as continuous variable, TPG had no significant effect on mortality. Using a TPG of 15 in the analysis rather than 12 produced similar results (not shown). On multivariate analysis, age more than one yr, transplant after 2003 and pre-transplant hospitalization status were significant predictors of overall mortality.

Among the 1322 patients with CMP, 1111 $(84 \%)$ had dilated CMP, 151 (11.4\%) had restrictive CMP, and 60 (4.5\%) had hypertrophic CMP. The 1135 patients without catheterization data had a similar distribution of CMP subtypes. Among patients with catheterization data available, there were more patients with RCM in the PHTN group (Table 2), but the overall mortality was not significantly different between diagnoses: DCM: 312 (28\%), RCM: 32 (21\%), and HCM: $16(27 \%)(\mathrm{p}=0.2)$.

When patients were stratified by age, PHTN had no effect on early mortality in children transplanted $<1 \mathrm{yr}$ age, but it was associated with increased mortality in children $>1 \mathrm{yr}$ age. There was no era effect apparent in early survival in PHTN group before vs. after 2003 when pulmonary vasodilator therapy became widely available.

\section{Discussion}

In our analysis of the UNOS database, we have found short-term mortality at one and three months post-transplant to be significantly higher in pediatric cardiomyopathy patients with PHTN than if the TPG is normal. There was no effect of era on mortality before and after 2003 when pulmonary vasodilator therapy became widely available. The mortality influence of PHTN was not seen in infants. In patients with PHTN, ischemic time of the transplanted heart or use of oversized donors did not have a significant effect on mortality.

Heart transplantation is an excellent option for children with end-stage cardiomyopathy, some forms of complex congenital heart disease and some infants and children with failed surgical interventions. Without transplant children with end-stage cardiomyopathy have a poor prognosis (9). PHTN in patients awaiting transplant can complicate postoperative care. Several studies have shown that elevated TPG or PVR is associated with high post-transplant mortality $(1-3,10-15)$. Historically mortality was found to be higher in children with PHTN, particularly in those who were over one yr of age (3). PHTN can preclude offering transplant to children with end-stage heart disease. We have found that overall mortality post-transplant is significantly higher in pediatric patients with PHTN but not in infants. Infants seem protected from mortality from PHTN as the PVR is rarely fixed and it seems to decrease more rapidly after heart transplantation than in children or adults (3). The long-term mortality in the PHTN group is not significantly greater than with normal pulmonary pressures. This could be because the long-term mortality more often is caused by factors other than PHTN that may be similar in both groups. Although the initial small difference in early mortality persists long term, the mortality from other causes is significantly higher making the difference not statistically significant.

Recent studies in adults suggest that PHTN if reversible is not associated with poor transplant outcomes and that these patients can be transplanted safely $(6,16-20)$. In pediatric patients with cardiomyopathy and PHTN, it was shown that use of sildenfil, bosentan, nitric oxide (21), prostacyclin (8), PGE1 (22), and ventricular assist devices (23) may improve outcomes comparable to patients without PHTN and that pulmonary resistance index normalized early after transplantation (24). However, the impact of the current practice of excluding patients with significantly elevated non-reactive PVR on outcomes cannot be excluded (25). Contrary findings in other studies have shown that PHTN even if reactive is associated with poor outcomes (26) and increased mortality (27). To evaluate the effects of era on outcomes, we performed subgroup analysis to compare mortality in patients transplanted before and after 2003 when the use of selective pulmonary vasodilators became common. The survival has significantly improved in both groups transplanted after 2003 (Table 4), but mortality in the PHTN group still remains significantly higher than the no-PHTN group.

Previous studies have shown that in patients with PHTN, transplanting a heart with longer ischemic time may increase mortality (28). However in our study, we did not notice any effect of ischemic time on mortality in PHTN patients. It was also found in previous studies that use of an oversized donor may be beneficial in patients with PHTN (29). When we compared outcomes in the PHTN group, there was a trend toward lower mortality with oversized DRWR (28\%) compared to ideal DRWR (30\%) and low DRWR (41\%), but it did not reach statistical significance $(\mathrm{p}=0.4)$. 
Despite advances in management strategies for pediatric cardiomyopathy patients with PHTN, early survival is inferior in these patients compared to those without PHTN. Although PHTN had no detrimental effect on early post-transplant morbidity such as length of post-transplant hospital stay, need for reoperations or dialysis, there were no data available in the UNOS database about indicators of right heart failure such as need for ECMO or assist device support post-transplant and thus could not be analyzed.

\section{Limitations}

This study was performed using the UNOS database. Limitations that are inherent to a retrospective database study apply here. Only $54 \%$ of children with cardiomyopathies had cardiac catheterization data available and if all had data, our analysis may have produced different conclusions. A second limitation of the study is that although we had data on the number of patients who were on inotropes/ vasodilators at the time of cardiac catheterization, the reversibility of PHTN was not documented and thus could not be analyzed.

\section{Conclusions}

PHTN continues to have a significant impact on early post-transplant mortality in pediatric patients with cardiomyopathies despite availability of agents that lower PVR. The use of oversized donors or grafts with shorter ischemic times does not seem to affect the outcomes. Infants seem to be protected from the effects of PHTN.

\section{Author contributions}

Buddhe Sujatha: data collection and analysis, drafting article; Du Wei: statistics; Thomas L'Ecuyer: concept/design, critical revision.

\section{Conflict of interest}

None.

\section{Disclosures}

None.

\section{References}

1. Bourge RC, Naftel DC, Costanzo-Nordin MR, et al. Pretransplantation risk factors for death after heart transplantation: A multiinstitutional study. The Transplant Cardiologists Research Database Group. J Heart Lung Transplant 1993: 12: 549-562.

2. Erickson KW, Costanzo-Nordin MR, O'Sullivan EJ, et al. Influence of preoperative transpulmonary gradient on late mortality after orthotopic heart transplantation. J Heart Transplant 1990: 9: 526-537.

3. Funushima N, Gundry SR, Razzouk AJ, Bailey LL. Risk factors for graft failure associated with pulmonary hypertension after pediatric heart transplantation. J Thorac Cardiovasc Surg 1994: 107: 985-989.

4. Shaddy RE. Pulmonary hypertension in pediatric heart transplantation. Prog Pediatr Cardiol 2000: 11: 131-136.

5. Shaddy RE, Naftel DC, Kirklin JK, et al. Outcome of cardiac transplantation in children. Survival in a contemporary multi-institutional experience. Pediatric Heart Transplant Study. Circulation 1996: 94(9 Suppl): II69-II73.

6. Tenderich G, Koerner MM, Stuettgen B, et al. Pre-existing elevated pulmonary vascular resistance: Long-term hemodynamic follow-up and outcome of recipients after orthotopic heart transplantation. J Cardiovasc Surg (Torino) 2000: 41: 215-219.

7. Ofori-Amanfo G, Hsu D, Lamour JM, et al. Heart transplantation in children with markedly elevated pulmonary vascular resistance. J Heart Lung Transplant 2006: 25: S49-S50.

8. Fenton MJ, Chubb H, McMahon AM, Rees P, Elliott MJ, BurCH M. Heart and heart-lung transplantation for idiopathic restrictive cardiomyopathy in children. Heart 2006: 92: 85-89.

9. Russo LM, WebBer SA. Idiopathic restrictive cardiomyopathy in children. Heart 2005: 91: 1199-1202.

10. Kirklin JK, Naftel DC, Kirklin JW, Blackstone EH, White-Williams C, Bourge RC. Pulmonary vascular resistance and the risk of heart transplantation. J Heart Transplant 1988: 7: 331-336.

11. Costard-Jackle A, Hill I, Schroeder JS, Fowler MB. The influence of preoperative patient characteristics on early and late survival following cardiac transplantation. Circulation 1991: 84(5 Suppl): III329-III337.

12. McCarthy JF, McCarthy PM, Massad MG, et al. Risk factors for death after heart transplantation: Does a singlecenter experience correlate with multicenter registries? Ann Thorac Surg 1998: 65: 1574-1578; discussion 8-9.

13. Gorlitzer M, Ankersmit J, Fiegl N, et al. Is the transpulmonary pressure gradient a predictor for mortality after orthotopic cardiac transplantation? Transpl Int 2005: 18: 390395.

14. Murali S, Kormos RL, Uretsky BF, et al. Preoperative pulmonary hemodynamics and early mortality after orthotopic cardiac transplantation: The Pittsburgh experience. Am Heart J 1993: 126: 896-904.

15. Frigerio M, Gronda E, Danzi GB, et al. [Short-term survival after heart transplantation: The relationships between preoperative hemodynamics, organ function and postoperative clinical events]. G Ital Cardiol 1995: 25: 1-9.

16. Zeng Z, Jiang Z, Wang CS, Luo H, Huang YF, Jin XH. Preoperative evaluation improves the outcome in heart transplant recipients with pulmonary hypertension - retrospective analysis of 106 cases. Transplant Proc 2010: 42: 3708-3710.

17. John R, Rajasinghe H, Chen JM, et al. Impact of current management practices on early and late death in more than 500 consecutive cardiac transplant recipients. Ann Surg 2000: 232: 302-311.

18. Goland S, CZer LS, Kass RM, et al. Pre-existing pulmonary hypertension in patients with end-stage heart failure: Impact on clinical outcome and hemodynamic follow-up after orthotopic heart transplantation. J Heart Lung Transplant 2007: 26: 312 318.

19. Klotz S, Wenzelburger F, Stypmann J, et al. Reversible pulmonary hypertension in heart transplant candidates: To transplant or not to transplant. Ann Thorac Surg 2006: 82: $1770-1773$. 


\section{Buddhe et al.}

20. Drakos SG, Kfoury AG, Gilbert EM, et al. Effect of reversible pulmonary hypertension on outcomes after heart transplantation. J Heart Lung Transplant 2007: 26: 319-323.

21. Daftari B, Alejos JC, Perens G. Initial experience with sildenafil, bosentan, and nitric oxide for pediatric cardiomyopathy patients with elevated pulmonary vascular resistance before and after orthotopic heart transplantation. J Transplant 2010: 2010: 656984 .

22. Iberer F, Wasler A, Tscheliessnigg K, et al. Prostaglandin E1-induced moderation of elevated pulmonary vascular resistance. Survival on waiting list and results of orthotopic heart transplantation. J Heart Lung Transplant 1993: 12: 173-178.

23. Liden H, Haraldsson A, Ricksten SE, Kuellman U, WIKLUND L. Does pretransplant left ventricular assist device therapy improve results after heart transplantation in patients with elevated pulmonary vascular resistance? Eur J Cardiothorac Surg 2009: 35: 1029-1034; discussion 34-5.

24. GaJARski RJ, Towbin JA, Bricker JT, et al. Intermediate follow-up of pediatric heart transplant recipients with elevated pulmonary vascular resistance index. J Am Coll Cardiol 1994: 23: $1682-1687$.
25. Webber SA, Fricker FJ, Michaels M, et al. Orthotopic heart transplantation in children with congenital heart disease. Ann Thorac Surg 1994: 58: 1664-1669.

26. Butler J, Stankewicz MA, Wu J, et al. Pre-transplant reversible pulmonary hypertension predicts higher risk for mortality after cardiac transplantation. J Heart Lung Transplant 2005: 24: 170-177.

27. Chen JM, Levin HR, Michler Re, Prusmack CJ, Rose EA, AARONSON KD. Reevaluating the significance of pulmonary hypertension before cardiac transplantation: Determination of optimal thresholds and quantification of the effect of reversibility on perioperative mortality. J Thorac Cardiovasc Surg 1997: 114: 627-634.

28. Kawaguchi A, Gandjbakhch I, Pavie A, et al. Cardiac transplant recipients with preoperative pulmonary hypertension. Evolution of pulmonary hemodynamics and surgical options. Circulation 1989: 80(5 Pt 2): III90-III96.

29. Tamisier D, Vouhe P, Le Bidois J, Mauriat P, Khoury W, LeCA F. Donor-recipient size matching in pediatric heart transplantation: A word of caution about small grafts. J Heart Lung Transplant 1996: 15: 190-195. 